\title{
Expression of GPD1 and SIP18 genes during rehydration in active dry industrial Saccharomyces cerevisiae cider-making yeast strains (ADY)
}

\author{
Anna Goncerzewicz ${ }^{\bowtie}$, Karolina Kamińska-Wojteczek, Izabella Młynarczyk and \\ Anna Misiewicz
}

Prof. Wacław Dabrowski Institute of Agricultural and Food Biotechnology, Department of Microbiology, Culture Collection of Industrial Microorganisms, Warsaw, Poland

\begin{abstract}
In this study we determined the influence of different sugar concentration in media, time of rehydration and type of strain on relative expression level of GPD1 and SIP18 genes of active dry cider-making yeast strains, followed by the assessment of the impact of rehydration on the fermentation process. High expression of SIP18 at the beginning of rehydration was shown to be due to high transcription of the gene during the drying process. High sugar concentrations of media initiated transcription of the GPD1 gene and triggered the cellular glycerol biosynthesis pathway in examined strains. Rehydration time and type of strain showed to have no statistically significant impact on the course of the fermentation; RT qPCR results depended mainly on the time of rehydration and sugar concentration of the medium. This is the first attempt to confront rehydration time and molecular mechanisms acting upon rehydration with the course of the fermentation process.
\end{abstract}

Key words: gene expression, yeasts, wine, fermentation biotechnology, yeast physiology

Received: 04 August, 2016; revised: 22 February, 2017; accepted: 25 February, 2017; available on-line: 09 June, 2017

e-mail: a.goncerzewicz@nencki.gov.pl (AG); anna.misiewicz@ibprs.pl (AM)

Abbreviations: ADY, active dry yeast strains; HOG, high osmolarity glycerol pathway; GPD1, gene encoding NAD-dependent glycerol3-phosphate dehydrogenase; SIP18, gene encoding phospholipidbinding hydrophilin; cfu, colony-forming unit; Cq, quantification cycle; RT qPCR, Real Time quantitative Polymerase Chain Reaction; SD, standard deviation; CV, coefficient of variance; LSC2 gene encoding beta subunit of succinyl-CoA ligase; QCR9, gene encoding subunit 9 of the ubiquinol cytochrome-c reductase complex; $T E F \_Q$, gene encoding translation elongation factor $1 a$; ROS, reactive oxygen species.

\section{INTRODUCTION}

Very early in the development of human civilization yeast was found to be the basis for preparation of alcoholic beverages. The main metabolic process occurring in winemaking is alcoholic fermentation consisting of biotransformation of glucose and fructose contained in the fruit must into ethanol and $\mathrm{CO}_{2}$. Other compounds, such as higher alcohols, esters, glycerol, diacetyl, acetoin, are also formed in the process. Fermentation may occur spontaneously, as discovered by Pasteur in the 19th century, because of the presence of yeasts dwelling on the surface of vineyards, grapes and wineries (Rosini, 1984; Pretorius, 2000; Mecado \& Combina, 2010; Mecado et al., 2011), or by means of addition of pure yeast starter cultures to the must (Valero et al., 2007; Chambers \& Pretorius, 2010).

Introduction of active dry yeasts in the wine-making process in the 1970 s led to a significant increase in the share of the products on the fermentation market and decreased the usage of other forms of pure yeast cultures. ADYs are also used as an alternative to the traditional starter cultures in the form of suspensions or compressed yeast mass also in other branches of fermentation industry, such as baking or brewing industry (Lee, 2015). This form of yeast ensures rapid and reliable fermentation and reduces the risk of sluggish or stuck fermentation and of microbial contamination (Valero et al., 2007).

The manufacturers of ADY products recommend preliminary hydration of yeasts by means of preparing suspensions in water or sugar-containing media at the temperature of $35-40^{\circ} \mathrm{C}$ and over different times (Kraus et al., 1981; Peña et al., 1992; Soubeyrand et al., 2006).

Regeneration of yeast cells during rehydration was shown to be of key importance due to the triggering of the processes of metabolism and adaptation to the environment so that fermentation could be effectively started by Saccharomyces cerevisiae cells (Novo et al., 2007). ADY cells through the production, rehydration and fermentation process undergo a "stressful journey" which leads to numerous metabolic modifications (Banuett, 1998; Fu \& Chen, 2011; Pénicaud et al., 2014). During this process yeast biomass is multiplied in aerobic conditions, which results in increased cell damage due to the activity of free radicals (Gomez-Pastor et al., 2010). At the end of the drying stage, stress response is also generated by the lack of nutrients (Cerrutti et al., 2000). Changes in cell membrane permeability occur upon drying and subsequent rehydration while the changes in water saturation induce the osmotic stress. Next, during vinification, yeasts ferment the ingredients of must that are completely different from the synthetic growth media and characterized by high concentration of sugars and other ingredients as well as low availability of oxygen. Due to such changes in their environment, cells adjust their metabolism in order to survive and take up other functions (Mannazzu et al., 2008; Diaz-Hellin et al., 2014).

Several factors affect the viability of cells during rehydration, including the preceding drying procedure, intracellular trehalose level in dried cells, duration and temperature of rehydration and the $\mathrm{pH}$ of the rehydration medium (Sales et al., 2000; Soubeyrand et al., 2006; Ferrarini et al., 2007). These factors affect the structure of the cellular wall determining its permeability for metabolites and ions and thus the cells' viability and activity. On 
Table 1. Rehydration media used in this study.

\begin{tabular}{|c|c|c|c|c|c|c|}
\hline Rehydration media & $\begin{array}{l}\text { Apple juice } \\
\text { (ml l-1 water) }\end{array}$ & $\begin{array}{l}\text { Final sucrose content } \\
\left(\mathrm{g} \mathrm{I}^{-1}\right)\end{array}$ & $\begin{array}{l}\text { Ammonium sulphate } \\
\left(\mathrm{g} \mathrm{l}^{-1}\right)\end{array}$ & $\begin{array}{l}\text { Ammonium phosphate } \\
\left(\mathrm{g} \mathrm{l}^{-1}\right)\end{array}$ & $\begin{array}{l}\text { Citric acid } \\
\left(\mathrm{g} \mathrm{I}^{-1}\right)\end{array}$ & $\mathrm{pH}$ \\
\hline \multirow{2}{*}{ apple must } & \multirow{2}{*}{212} & 210 & \multirow{2}{*}{4.2} & \multirow{2}{*}{1} & \multirow{2}{*}{4.5} & \multirow{2}{*}{3.8} \\
\hline & & 300 & & & & \\
\hline
\end{tabular}

the other hand, cells undergoing rehydration are capable of molecular-level responses, triggering and switching gene expression depending on the environmental conditions and presence of assimilated sugars. Therefore, a number of combinations of reaction conditions, strains and media are being tested for suitability in the rehydration phase with regard to increasing the cell viability and activity during vinification (Pérez-Torrado et al., 2002; Vaudano et al., 2010; Diaz-Hellin et al., 2014; GameroSandemetrio et al., 2014). To date, little information has been available on fermentation yields following inoculation of medium different than grape with rehydrated cells under industrial conditions. Also, previous analyses carried out by other research groups showed differences in fermentative behavior and gene expression between wine yeasts.

The transfer of ADY to a new medium leads to an increase in the transcription of genes related to protein synthesis (Gasch et al., 2000). Upon inoculation and induction of fermentation cells obtain a resistance to osmotic stress, which is the key factor regulating the cell survival (Hohmann, 2002; Mager \& Siderius, 2002). The response of $S$. cerevisiae to the loss of water and high concentration of sugars in the environment is based particularly on the well-described high osmolarity glycerol (HOG) pathway, which is regulated by the expression of more than 100 genes (Posas, 1998; Rodriguez-Peña et al., 2010; Babazadeh et al., 2014). One of the key genes involved in the process is GPD1 responsible for glycerol production (Albertyn et al., 1994, Hubmann et al., 2011, Petelenz-Kurdziel et al., 2013). Increased intracellular levels of glycerol reduce the activity of water in cytosol thus leading to reduced outflow of water into the environment. Another gene of interest in this study was SIP18 encoding the hydrophilin family of proteins (Singh et al., 2005; Rodriguez-Porrata et al., 2011; Rodriguez-Porrata et al., 2012). Hydrophilins act as antioxidants and stabilizers of cellular membrane and other proteins thus playing a key role in survival under significant water loss conditions (Tunnacliffe \& Wise, 2007; Rodríguez-Porrata et al., 2012). So far, molecular mechanism triggered in the process as well as the effect of medium's concentration and composition on the course of fermentation have still remained poorly understood.

This study analyzed the expression of GPD1 and SIP18 genes involved in the response of dehydrated cells of industrial Saccharomyces cerevisiae yeast cells during the first 30 minutes of the rehydration process. In the experiment different sugar concentrations, time of rehydration and strains were taken into account as the key factors of this response. This study was a continuation of research on brewers, wine-, cider- and mead-making yeasts and their dried formulations carried out at micro technical scale in recent years (Misiewicz \& Ilnicka-Olejniczak, 1996; Misiewicz et al., 2015).

\section{MATERIALS AND METHODS}

Yeast strains, media and fermentation conditions. The study material consisted of two selected cider-mak- ing Saccharomyces cerevisiae strains - KKP 3 and KKP 39 from the Culture Collection of Industrial Microorganisms of the prof. Wacław Dabrowski Institute of Agricultural and Food Biotechnology (http://www.ibprs.pl/ $\mathrm{bazy} / \mathrm{cim} /, 05.2015)$. The strains were initially isolated from the skin of apple fruit used afterwards for production of cider. These particular strains were selected because they offer dependability under difficult wine-making conditions and have a high fermentation rate tested in our previous studies (Misiewicz \& Ilnicka-Olejniczak, 1991; Ilnicka-Olejniczak et al., 1996). ADY were made locally, at laboratory scale for the experiment purpose, in lyophilized form. Each sample contained about $3 \times 10^{6}$ cfu which was confirmed according to PN-ISO $21527-$ 1:2009. Apple musts were obtained from apple fruits harvested from Tarczyn and Nasielsk area and purchased from Binder International (Warsaw, Poland). Apple juice $\left(212 \mathrm{ml} \mathrm{l}^{1}\right)$ was diluted with fresh water and then sucrose was added to obtain required sugar concentration. Additionally, citric acid (up to $4.5 \mathrm{~g} \mathrm{l}^{1}$ ), ammonium sulphate (up to $4.2 \mathrm{~g} \mathrm{l}^{1}$ ) and ammonium phosphate (up to $1 \mathrm{~g} \mathrm{l}^{1}$ ) were added and then the mixture was pasteurized for $15 \mathrm{~min}$ at $104^{\circ} \mathrm{C}$. Composition of the media is presented in Table 1.

Samples of $3 \times 10^{6} \mathrm{cfu}$ of dried yeast formulations were rehydrated with $1 \mathrm{ml}$ of medium heated to $40^{\circ} \mathrm{C}$. The suspension was vortexed for $10 \mathrm{~s}$ and incubated for 0 (workup immediately following the initial vortexing step), 5, 15 and 30 minutes at the same temperature. After incubation, the suspension was vortexed once again (5 s) and frozen in liquid nitrogen for subsequent analyses. Fermentation trials were carried out in $500 \mathrm{ml}$ flat-bottom flasks stopped with fermentation tubes, containing $250 \mathrm{ml}$ of apple must, at the temperature of $27^{\circ} \mathrm{C}$, for 33 days. The flasks were then inoculated with the previously hydrated yeast formulation. The weight loss associated with the liberation of $\mathrm{CO}_{2}$ was measured daily. After fermentation, yeast was removed by filtration and filtrate was used for further analyses. All the assays were performed in triplicate.

Fermentation products analysis. Ciders were distillated and afterwards the ethanol percentage, volatile acidity, total extract were determined according to validated standard methods PN-90 A-791120/04, PN-90 A-79120/08, PN-90 A-79120/07, PN-90 A-79120/05, respectively. Reducing sugars were measured according to Miller (1959).

RNA extraction and cDNA synthesis. RNA extraction was performed using a commercially available kit (PureLink RNA Mini Kit, Ambion, Life Technologies). The yeast lysis was performed using mechanical methods: rehydrated yeast suspension was mashed with a pestle to release the intracellular lysate. Next, $500 \mu \mathrm{l}$ of lysis buffer with 2 -mercaptoethanol $\left(10 \mu \mathrm{ml}^{1}\right)$ was added to each sample and manufacturer's procedure was followed. Genomic DNA was eliminated from the samples by DNase treatment according to the manufacturer's description (RNase Free DNase Set, Qiagen). RNA quality and concentration were assessed spectrophotometrically and by electrophoresis in 1\% agarose. The RNA samples were preserved at $80^{\circ} \mathrm{C}$. 
Table 2. Genes and primers used for the RT qPCR experiments.

\begin{tabular}{|c|c|c|c|c|c|}
\hline Gene & Primer & Sequence $\left(5^{\prime} \rightarrow 3^{\prime}\right)$ & $\begin{array}{l}\text { Amplicon } \\
\text { sizes (bp) }\end{array}$ & Efficiency & Reference \\
\hline GPD1 & $\begin{array}{l}\text { GPD1_U } \\
\text { GPD1_L }\end{array}$ & $\begin{array}{l}\text { GGTTGGAAACATGTGGCTCT } \\
\text { GGCAGGTTCTTCATTGGGTA }\end{array}$ & 91 & 2.00 & \multirow{4}{*}{ Vaudano et al. (2009) } \\
\hline SIP18 & $\begin{array}{l}\text { SIP18_U } \\
\text { SIP18_L }\end{array}$ & $\begin{array}{l}\text { CCAAATCCTCCAACAAGGAA } \\
\text { GTCTTCCAATCGTTCGCAAT }\end{array}$ & 145 & 2.02 & \\
\hline QCR9 & $\begin{array}{l}\text { QCR9_U } \\
\text { QCR_L }\end{array}$ & $\begin{array}{l}\text { ATCTITGCAGGTGCCTTTGT } \\
\text { GCAGCTATTCGAGCCTTGAC }\end{array}$ & 113 & 1.91 & \\
\hline LSC2 & $\begin{array}{l}\text { LSC2_U } \\
\text { LSC2_L }\end{array}$ & $\begin{array}{l}\text { GCGTCCAGTCAAGGTGGTAT } \\
\text { ACTCTTGGCAACATCCTTGG }\end{array}$ & 126 & 1.88 & \\
\hline TEF_Q & $\begin{array}{l}\text { TEF-Q_F } \\
\text { TEF-Q_R }\end{array}$ & $\begin{array}{l}\text { ACGCCATTGAACAACCATCTAGACCAA } \\
\text { CAGCTGGGGCGAAAGTAACAACCATA }\end{array}$ & 153 & 1.96 & Nardi et al. (2010) \\
\hline
\end{tabular}

cDNA was synthesized from $50 \mathrm{ng} \mu \mathrm{l}^{-1}$ of total RNA using RevertAid First Strand cDNA Synthesis Kit (Thermo Scientific) with oligo (dT) priming and then diluted to the required concentration. This was followed by RNAse treatment according to the manufacturer's instructions. The cDNA samples were stored at $80^{\circ} \mathrm{C}$.

Primers. Primers used in this study were designed by Vaudano and coworkers (2009) and Nardi and coworkers (2010). Primers were purchased from Genomed (Genomed S.A., Warsaw, Poland). Each primer was previously tested on $1.5 \%(\mathrm{w} / \mathrm{v})$ agarose gel to verify its specificity. Table 2 shows the sequence of primers used in this study, the respective amplicon sizes, efficiency of the RT qPCR reactions and corresponding references.

Analysis of the reference genes. The gene used as the reference for the comparison of expression in various rehydration conditions was selected on the basis of its stability in tested samples. The most reliable (in statistical terms) reference gene for the assessment of relative gene expression was selected using the BestKeeper 1.0 software that analyzed the standard deviation (SD) and coefficient of variance $(\mathrm{CV})$ for replicate $\mathrm{Cq}$ values of the reference genes in various yeast strains and rehydration media (Pfaffl et al., 2004).

RT qPCR. RT qPCR analysis was performed in a Rotor Gene 6000 instrument (Qiagen) using the doublestranded-DNA-specific fluorochrome SYBR Green. Reactions were performed in a volume of $25 \mu$ l containing $1 \mu \mathrm{l}$ of $\mathrm{cDNA}, 0.6 \mu \mathrm{l}(10 \mu \mathrm{M})$ of forward and reverse primers and $12.5 \mu \mathrm{l}$ of $2 \times \mathrm{SYBR}$ Green master mix (Maxima SYBR Green qPCR Master Mix, Thermofisher Scientific).

Priming temperature and RT qPCR programs were determined on the basis of temperature gradient tests. The reactions were run for 40 cycles with denaturation at $95^{\circ} \mathrm{C}$ for $30 \mathrm{~s}$, annealing at $59^{\circ} \mathrm{C}$ for $30 \mathrm{~s}$ and extension at $72^{\circ} \mathrm{C}$ for $17 \mathrm{~s}$. An initial $10 \mathrm{~min}$ denaturation step at $95^{\circ} \mathrm{C}$ was used. In addition, product melting was assessed at the end of the reaction so as to verify the reaction specificity (Valasek \& Repa, 2005). Reactions conducted on the test samples provided Cq values that described the formation of the product upon the assumption of a constant actual reaction yield. The threshold line was determined automatically by the software and the $\mathrm{Cq}$ values were uploaded to an Excel file for analysis using the double delta method (Livak \& Schmittgen, 2001). All experiments were performed with negative control.

Statistical analysis. All determinations and experiments were performed in triplicate and the results presented are the average values of three determinations. The Statistica version 10 (StatSoft Poland, part of Stat-
Soft Inc.) software was used to statistically evaluate experimental data. The ANOVA multifactor analysis of variance and LSD test $(\alpha=0.05)$ were performed to evaluate the significance of variation in expression and metabolite synthesis for different media, time of rehydration and strains. The fulfillment of the ANOVA requirement of homogeneity of variances was evaluated by means of the Shapiro-Wilks test $(n<50)$. Statistical data for fermentation parameters were arranged according to Szterk (2015).

\section{RESULTS}

\section{Fermentation trial}

In order to assess the effect of rehydration time on the course of fermentation carried out by tested strains, $\mathrm{CO}_{2}$ emission levels were monitored together with fermentation process parameters such as ethanol concentration, volatile acidity, titratable acidity, total extract, or reducing sugars concentration.

As shown in Fig. 1 and Fig. 2, the loss of $\mathrm{CO}_{2}$ following rehydration of cider-making yeast strains KKP 3 and KKP 39 was similar and depended on the sugar content in medium. The loss of $\mathrm{CO}_{2}$ in strains rehydrated and fermented at concentrations of $210 \mathrm{~g} \mathrm{l}^{-1}$ was higher than in the medium with sugar concentration of $300 \mathrm{~g} \mathrm{l}^{-1}$ and ranged from $12.23 \mathrm{~g}$ to $19.20 \mathrm{~g}$ for strain KKP 3. In the medium with sugar concentration of $300 \mathrm{~g} \mathrm{l}^{-1}$ the loss of $\mathrm{CO}_{2}$ for KKP 3 ranged from $13.75 \mathrm{~g}$ to $15.70 \mathrm{~g}$ with the exception for sample 300/T15 where it reached 24.73 . Similar observations were made for strain KKP 39 containing sugar at regular industrial level, where the parameter ranged from $12.05 \mathrm{~g}$ to $15.70 \mathrm{~g}$. In case of fermentation using rehydrated yeast cells for KKP 39 strain with sugar concentration of $300 \mathrm{~g} \mathrm{l}^{-1}$ the reached level of $\mathrm{CO}_{2}$ production was lower than in other samples and ranged from 10.88 to $13.20 \mathrm{~g}$.

Analysis of young ciders obtained with fermentation of strains in different time of rehydration and sugar concentration was presented in Table 3 .

The ethanol level was found to depend mainly on the amount of sugar in the medium $(p<0.01)$. Selection of the strains (KKP 3 or 39) and initial rehydration time $(0,5,15$ and 30$)$ affected the results to a minor extent $(p<0.05)$. The highest quantity of ethanol was produced by strain KKP 39 after 5 minutes of preliminary rehydration in the medium with the sugar content of $210 \mathrm{~g}$ $\mathrm{l}^{-1}$; the ethanol concentration reached $15.2 \%$.

The volatile acidity values depended on all factors; mainly medium and strain $(p<0.01)$, still statistically sig- 


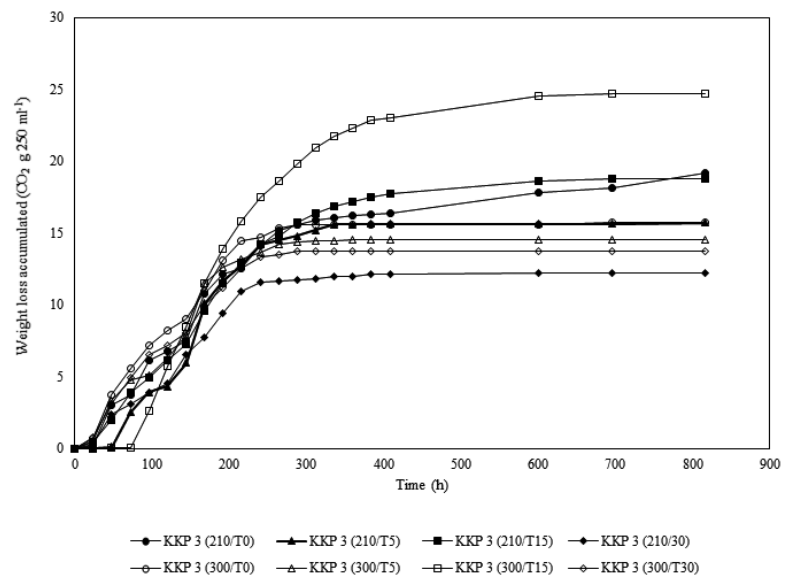

Figure 1. $\mathrm{CO}_{2}$ production curves for strain KKP 3.

The figure shows the profile of strain rehydrated with medium:

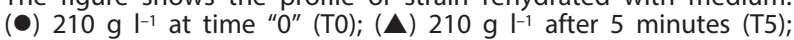
(a) $210 \mathrm{~g} \mathrm{l}^{-1}$ after 15 minutes (T15); ( ) $210 \mathrm{~g} \mathrm{l}^{-1}$ after 30 minutes (T30); (O) $300 \mathrm{~g} \mathrm{l}^{-1}$ at time "0" (T0); ( $\triangle$ ) $300 \mathrm{~g} \mathrm{l}^{-1}$ after 5 minutes (T5); ( $\square) 300 \mathrm{~g} \mathrm{l}^{-1}$ after 15 minutes (T15); ( $\left.\diamond\right) 300 \mathrm{~g} \mathrm{l}^{-1}$ after 30 minutes (T30). Standard deviation was less than $5 \%$ in all cases.

nificant $(p<0.05)$ but less important was the time of rehydration. The highest levels of volatile acidity, of 1.281.43 , were found for the strain KKP 39 in the must containing sugar at concentration of $300 \mathrm{~g} \mathrm{l}^{-1}$. Similar values were observed in fermentation trials with strain KKP 3 in the high-sugar media. The lowest levels were obtained for all strains at sugar concentration of $210 \mathrm{~g} \mathrm{l}^{-1}$.

No statistical differences were observed in the titratable acidity for all tested strains. The only differences could be found in relation to the medium and time of rehydration $(p<0.03)$. Increase of this parameter was ob-

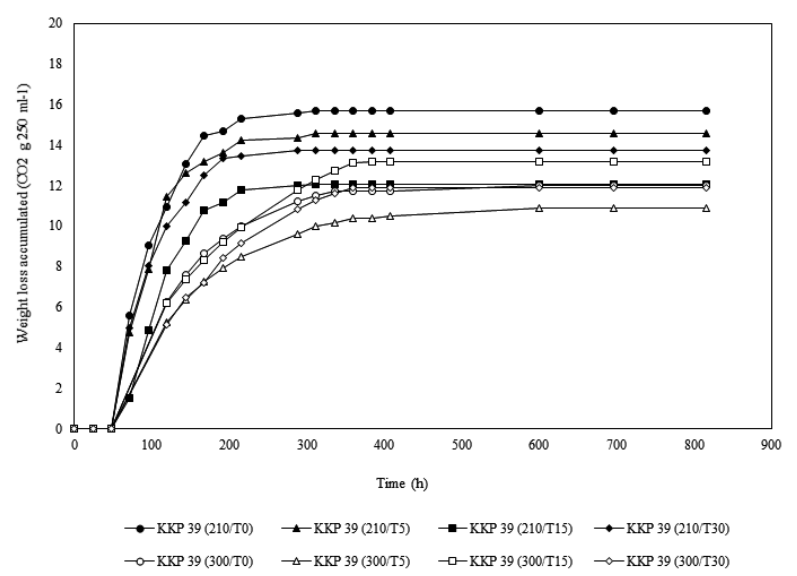

Figure 2. CO2 production curves for strain KKP 39.

The figure shows the profile of strain rehydrated with medium:

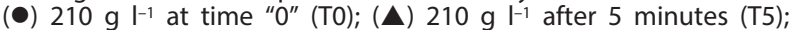
$210 \mathrm{~g} \mathrm{I}^{-1}$ after 15 minutes (T15); ( $\bullet 210 \mathrm{~g} \mathrm{l}^{-1}$ after 30 minutes (T30); (O) $300 \mathrm{~g} \mathrm{l}^{-1}$ at time "0" (TO); ( $\triangle$ ) $300 \mathrm{~g} \mathrm{l}^{-1}$ after 5 minutes (T5); ( $\square) 300 \mathrm{~g} \mathrm{l}^{-1}$ after 15 minutes (T15); ( $\left.\diamond\right) 300 \mathrm{~g} \mathrm{l}^{-1}$ after 30 minutes (T30). Standard deviation was less than $5 \%$ in all cases.

served during fermentation carried out using the KKP 3 strain at must sugar level of $210 \mathrm{~g} \mathrm{l}^{-1}$ without rehydration and after 5 minutes of rehydration; the measured values were 9.90 and $10.29 \mathrm{~g} \mathrm{l}^{-1}$ of tartaric acid, respectively.

Total extract (sum of proteins, sugars, pigments and tannins) did not significantly depend on the time of preliminary rehydration of yeast $(p>0.05)$. At the same time it depended only on the type of fermentation medium and used strain $(p<0.01)$. The process, when conducted using the KKP 39 and KKP 3 strains in the must with

Table 3. Analysis of ciders obtained from fermentation where strains were rehydrated in medium for different times and then used to inoculation apple must. Different letters next to the values represent significant differences at $a=0.05$.

\begin{tabular}{|c|c|c|c|c|c|c|c|c|}
\hline Strain & $\begin{array}{l}\text { Time of re- } \\
\text { hydration } \\
\text { (min) }\end{array}$ & $\begin{array}{l}\text { Sugar con- } \\
\text { centration } \\
\left(\mathrm{g} \mathrm{I}^{-1}\right)\end{array}$ & $\begin{array}{l}\text { Ethanol } \\
\text { (\% vol) }\end{array}$ & $\begin{array}{l}\text { Volatile acidity } \\
\text { (g l-1 acetic } \\
\text { acid) }\end{array}$ & $\begin{array}{l}\text { Titratable aci- } \\
\text { dity } \\
\text { (g l-1 tartaric } \\
\text { acid) }\end{array}$ & $\begin{array}{l}\text { Total extract } \\
\left(\mathrm{g} \mathrm{l}^{-1}\right)\end{array}$ & $\begin{array}{l}\text { Reducing sugars } \\
\left(\mathrm{g} \mathrm{l}^{-1}\right)\end{array}$ & $\mathrm{pH}$ \\
\hline \multirow{2}{*}{\multicolumn{2}{|c|}{ Fresh apple must }} & 210 & $0.00 \pm 0.00$ & $0.10 \pm 0.01$ & $7.23 \pm 0.01$ & $208.40 \pm 0.22$ & $220.50 \pm 1.60$ & \multirow{2}{*}{3.8} \\
\hline & & 300 & $0.00 \pm 0.00$ & $0.10 \pm 0.01$ & $6.75 \pm 0.01$ & $395.30 \pm 0.50$ & $310.60 \pm 2.30$ & \\
\hline \multirow{8}{*}{ KKP 3} & 0 & \multirow{4}{*}{210} & $12.87^{\mathrm{bla}} \pm 1.68$ & $0.61^{\text {allA }} \pm 0.03$ & $9.90^{\mathrm{bIl}}$ IIIA \pm 0.36 & $57.15^{\mathrm{alA}} \pm 8.35$ & $12.26^{\mathrm{alA}} \pm 0.01$ & \multirow{8}{*}{3.8} \\
\hline & 5 & & $12.80^{\mathrm{bla}} \pm 1.74$ & $0.74^{\text {al }} \| \mathrm{A} \pm 0.08$ & $10.29^{\mathrm{b} I I I A} \pm 0.45$ & $82.39^{\mathrm{al} A} \pm 0.03$ & $13.67^{\mathrm{al} A} \pm 0.01$ & \\
\hline & 15 & & $13.07^{\mathrm{bla}} \pm 0.83$ & $0.47^{\mathrm{al} A} \pm 0.04$ & $7.76^{\mathrm{bla}} \pm 0.11$ & $69.67^{\mathrm{alA}} \pm 2.33$ & $11.79 \mathrm{alA} \pm 0.67$ & \\
\hline & 30 & & $13.73^{\mathrm{bla}} \pm 1.51$ & $0.53^{\mathrm{alA}} \pm 0.06$ & $7.68^{\mathrm{bl} \mathrm{I}} \pm 0.16$ & $59.92^{\mathrm{alA}} \pm 4.83$ & $10.62^{\mathrm{alA}} \pm 0.07$ & \\
\hline & 0 & \multirow{4}{*}{300} & $12.40^{\mathrm{alA}} \pm 0.69$ & $1.37 \mathrm{bllA} \pm 0.09$ & 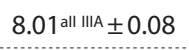 & $193.37^{\mathrm{blA}} \pm 4.65$ & $126.56^{\mathrm{blA}} \pm 6.33$ & \\
\hline & 5 & & $12.67^{\mathrm{alA}} \pm 0.83$ & $0.74^{\mathrm{bl} \mathrm{IA}} \pm 0.08$ & $7.90^{\mathrm{alll} A} \pm 0.11$ & $200.68^{\mathrm{bla}} \pm 5.35$ & $119.77^{\mathrm{bla}} \pm 3.11$ & \\
\hline & 15 & & $12.00^{\mathrm{alA}} \pm 0.69$ & $0.47^{\mathrm{bla}} \pm 0.04$ & $7.55^{\mathrm{alA}} \pm 0.14$ & $178.71^{\mathrm{blA}} \pm 8.26$ & $128.02^{\mathrm{bla}} \pm 0.43$ & \\
\hline & 30 & & $10.93^{\mathrm{alA}} \pm 1.01$ & $0.53^{\mathrm{BlA}} \pm 0.06$ & $8.09^{\mathrm{al}} \mathrm{IA} \pm 0.21$ & $207.19 \mathrm{bla} \pm 37.19$ & $124.89^{\mathrm{bla}} \pm 4.05$ & \\
\hline \multirow{8}{*}{ KKP 39} & 0 & \multirow{4}{*}{210} & $13.60^{\mathrm{bla}} \pm 0.69$ & $0.63^{\mathrm{allB}} \pm 0.03$ & $8.68^{\mathrm{b} I l} \mathrm{IIA} \pm 0.27$ & $76.76^{\mathrm{alB}} \pm 9.75$ & $23.38^{\mathrm{alB}} \pm 1.79$ & \multirow{8}{*}{3.8} \\
\hline & 5 & & $15.20^{\mathrm{bla}} \pm 1.06$ & $0.61^{\mathrm{al} I \mathrm{IB}} \pm 0.02$ & $8.40^{\mathrm{blll}} \pm 0.20$ & $65.55^{\mathrm{alB}} \pm 14.58$ & $20.79^{\mathrm{al}} \pm 0.45$ & \\
\hline & 15 & & $14.00^{\mathrm{bla}} \pm 0.00$ & $0.54^{\mathrm{alB}} \pm 0.23$ & $8.65^{\mathrm{blA}} \pm 0.41$ & $75.35^{\mathrm{alB}} \pm 8.79$ & $20.80^{\mathrm{alB}} \pm 0.08$ & \\
\hline & 30 & & $13.73^{\mathrm{bla}} \pm 0.46$ & $0.75^{\mathrm{alB}} \pm 0.03$ & $8.75^{\mathrm{bl} \| \mathrm{A}} \pm 0.38$ & $73.97^{\mathrm{alB}} \pm 14.58$ & $20.94^{\mathrm{alB}} \pm 0.27$ & \\
\hline & 0 & \multirow{4}{*}{300} & $12.67^{\mathrm{alA}} \pm 1.22$ & $1.37^{\mathrm{bllB}} \pm 0.09$ & $8.75^{\text {all IIIA }} \pm 0.21$ & $197.61^{\mathrm{blB}} \pm 9.24$ & $120.54^{\mathrm{blB}} \pm 2.06$ & \\
\hline & 5 & & $12.00^{\mathrm{alA}} \pm 0.40$ & $1.16^{\mathrm{bl} \mathrm{IIB}} \pm 0.24$ & $8.88^{\mathrm{alll}} \pm 0.06$ & $222.47^{\mathrm{blB}} \pm 10.88$ & $122.51^{\mathrm{blB}} \pm 2.63$ & \\
\hline & 15 & & $11.20^{\mathrm{alA}} \pm 0.40$ & $1.43^{\mathrm{blB}} \pm 0.08$ & $8.65^{\mathrm{al} A} \pm 0.04$ & $235.05^{\mathrm{blB}} \pm 9.48$ & $123.06^{\mathrm{blB}} \pm 1.23$ & \\
\hline & 30 & & $11.73^{\mathrm{alA}} \pm 0.23$ & $1.28^{\mathrm{blB}} \pm 0.06$ & $8.70^{\text {al IIA }} \pm 0.08$ & $219.32^{\mathrm{blB}} \pm 5.42$ & $120.07^{\mathrm{blB}} \pm 0.24$ & \\
\hline
\end{tabular}


Table 4. Statistic values of 3 candidate reference genes calculated using Best Keeper software ver. 1.0.

\begin{tabular}{llll}
\hline & LSC2 & QCR & TEF_Q \\
\hline $\mathrm{N}$ & 25 & 25 & 25 \\
$\mathrm{GM}[\mathrm{Cq}]$ & 21.44 & 21.82 & 15.30 \\
$\mathrm{AM}[\mathrm{Cq}]$ & 21.50 & 21.86 & 15.31 \\
$\mathrm{Min}[\mathrm{Cq}]$ & 18.69 & 17.85 & 13.98 \\
$\mathrm{Max}[\mathrm{Cq}]$ & 24.87 & 24.58 & 16.02 \\
$\mathrm{SD}[ \pm \mathrm{Cq}]$ & 1.52 & 0.85 & 0.45 \\
$\mathrm{CV}[\%$ Cq] & 7.06 & 3.88 & 2.92 \\
Min [x-fold] & -6.71 & -15.65 & -2.50 \\
$\mathrm{Max}[\mathrm{x}-$ fold] & 10.81 & 6.78 & 1.65 \\
$\mathrm{SD}[ \pm \mathrm{x}$-fold] & 2.87 & 1.80 & 1.36
\end{tabular}

Abbreviations: N: number of samples; GM [Cq]: geometric mean of $\mathrm{Cq}$; $\mathrm{AM}[\mathrm{Cq}]$ arithmetic mean of $\mathrm{Cq}$; Min [Cq] and Max [Cq]: extreme values of Cq; S.D. $[ \pm \mathrm{Cq}]$ : standard deviation of Cq; CV [\% Cq]: coefficient of variance expressed as the percentage of Cq level; Min [x-fold]: minimum value expressed as folds of expression; Max [x-fold]: maximum value expressed as fold of expression; S.D. [ $\pm \pm x-f o l d]$ : standard deviation in fold of expression.

sugar concentration of $210 \mathrm{~g} \mathrm{l}^{-1}$, was characterized by low quantities of total extract, ranging from 57.15 to $76.76 \mathrm{~g} \mathrm{l}^{-1}$. A nearly fourfold-higher total extract in cider was obtained in flasks in which fermentation was carried out using higher sugar concentrations of $300 \mathrm{~g} \mathrm{l}^{-1}$.

The differences in the level of reducing sugars in apple juice fermented with different ADY strains were statistically significant for sugar concentration in medium $(p<0.01)$ and also for the type of strain $(p<0.05)$. For KKP 3 strain reducing sugar content was between 10.62 and $13.67 \mathrm{~g} 1^{1}$. For KKP 39 almost two-fold-increase in reducing sugars in cider was obtained (20.79-23.38 $\left.\mathrm{g} \mathrm{l}^{1}\right)$. In medium with sugar concentration of $300 \mathrm{~g} 1^{1}$ proportionally smaller sugar amount was consumed and reducing sugars levels equaled about $120 \mathrm{~g}^{1}$.

\section{Selection of reference genes}

We tested the transcriptional variability of three genes, previously reported in literature as potential reference genes: LSC2 (coding beta subunit of succinylCoA ligase), QCR9 (coding subunit 9 of the ubiquinol cytochrome-c reductase complex) (Vaudano et al., 2010) and TEF $Q$ (coding translation elongation factor $1 \alpha$ ) (Nardi et al., 2010). SD ( $\pm \mathrm{Cq})$ and CV (\% Cq) values were calculated for each of the candidate reference genes in the samples so as to identify the overall stability of gene expression. One candidate reference gene LSC2 showed an SD value of 1.52 (higher than 1), which disqualified its utility as a reference gene. The remaining two genes (QCRO and TEF_Q) were selected for further analysis as they showed SD value of less than 1 . The TEF $Q$ gene was chosen as reference for gene expression studies, as the $\mathrm{CV}$ value for all replicates was 0.45 ; which was close to 0 and lower than the value of 0.85 obtained in the case of QCR gene. The parameters of the analyses were presented in Table 4.

\section{Expression of glycerol-3-phosphate dehydrogenase gene GPD1}

GPD1 gene codes NAD-dependent glycerol-3-phosphate dehydrogenase which is a key enzyme in the synthesis of glycerol, the main osmolyte accumulated by yeast cells. Its expression is regulated by high-osmolarity glycerol response pathway (HOG) (Bauer \& Pretorius, 2000). The intracellular glycerol levels increased by the expression of the gene are thought to counteract water loss by diminishing the water activity of the cytosol, thereby leading to water uptake (Albertyn et al., 1994).

As shown by the results, the expression of the gene in the rehydrated KKP 3 formulation increased significantly with the duration of the experiment $(p<0.01)$. In the medium with elevated sugar concentration the highest mRNA level of 7.56 was observed after 30 minutes of rehydration. A lower level of up to 3.79 was observed after 15 minutes of rehydration for the other cider-making strain, KKP 39. Similar expression was maintained after 30 minutes of rehydration. In addition, the experiment revealed that the medium containing the optimum sugar concentration also stimulated the expression of GPD1 gene in the KKP 3 strain after 30 minutes of rehydration $(p<0.01)$. The gene GPD1, despite being the most transcribed during the first phase of rehydration, showed a weak variation among examined strains $(p>0.05)$. All the expression data are shown in Fig. 3.

\section{Expression of the hydrophilin gene SIP18}

This gene codes phospholipid-binding hydrophilin which is es-

Figure 3. GPD1 gene expression for wine strains KKP 3 and KKP 39 during rehydration vs. time and medium:

(white bars) KKP 39 rehydrated in water; (white, stripped bars) KKP 3 rehydrated in water; (grey bars) KKP 39 rehydrated in $210 \mathrm{~g} \mathrm{l}^{-1}$ sucrose; (grey, stripped bars) KKP 3 rehydrated in $210 \mathrm{~g} \mathrm{l}^{-1}$ sucrose and (black bars) KKP 39 rehydrated in $300 \mathrm{~g} \mathrm{I}^{-1}$ sucrose; (black, stripped bars) KKP 3 rehydrated in $300 \mathrm{~g} \mathrm{I}^{-1}$ sucrose. Different letters above bars represent significant differences at $a=0.05$. 


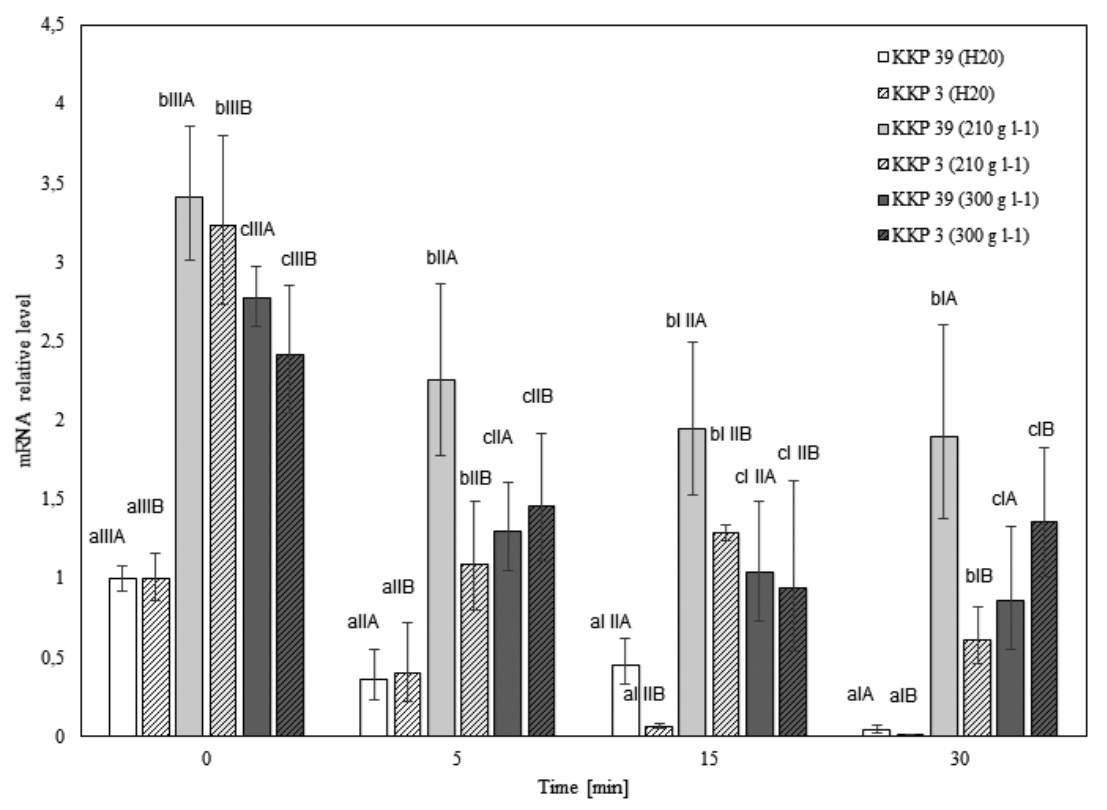

Figure 4. SIP18 gene expression for wine strains KKP 3 and KKP 39 during rehydration vs. time and medium:

(white bars) KKP 39 rehydrated in water; (white, stripped bars) KKP 3 rehydrated in water; (grey bars) KKP 39 rehydrated in $210 \mathrm{~g} \mathrm{I}^{-1}$ sucrose; (grey, stripped bars) KKP 3 rehydrated in $210 \mathrm{~g} \mathrm{l}^{-1}$ sucrose and (black bars) KKP 39 rehydrated in $300 \mathrm{~g} \mathrm{I}^{-1}$ sucrose; (black, stripped bars) KKP 3 rehydrated in $300 \mathrm{~g} \mathrm{l}^{-1}$ sucrose. Different letters above bars represent significant differences at $a=0.05$.

sential for overcoming the desiccation-rehydration process. Research showed that product of SIP18 gene acts as an inhibitor of apoptosis in yeast under dehydration stress, which was suggested by its antioxidative capacity through the reduction of ROS accumulation after $\mathrm{H}_{2} \mathrm{O}_{2}$ attack (Rodríguez-Porrata et al., 2010).

The experiment revealed that the expression of SIP18 gene was characterized by a significant decrease with the time of rehydration $(p<0.01)$. High levels of mRNA were maintained over several minutes at the beginning of the experiment to begin dropping rapidly after that time. The baseline expression level was quite high (up to 3.5) and the subsequent drop was marked. The largest differences in the expression of SIP18 gene in cider-making strains were observed in the case of strain KKP 39 rehydrated with a medium with sugar concentration of $300 \mathrm{~g} \mathrm{l}^{-1}$ : the gene expression dropped more than two times from the starting level of 2.77 within the first 5 minutes and continued with a slight decreasing trend afterwards $(p<0.01)$. The results are presented in Fig. 4.

\section{DISCUSSION}

The results of experiments presented in this study illustrate the phenomena occurring during the initial phase of rehydration of industrial active dried cider-making yeast strains (ADY) in the context of expression of the important genes GPD1 and SIP18 responsible for the cells response to osmotic stress. Currently, a small number of published papers focus on the topic of transcription mechanism during fermentation of different from grape must or drying processes. Only single manuscripts were published in recent years to describe the relative mRNA levels of the genes analyzed by means of RT qPCR or microarrays upon rehydration of strains (Novo et al., 2007; Vaudano et al., 2009; Vaudano et al., 2010).

In this study, yeast cells were rehydrated using a natural medium with addition of high levels of sugars; re- hydration was followed by fermentation trials, with assessment of parameters such as loss of $\mathrm{CO}_{2}$, titratable and volatile acidity, concentration of sugars, total extract, or alcohol concentration providing a clear general overview of the fermentation process with the use of the active Saccharomyces cerevisiae strains. The characteristics of the process were similar and uniform regardless of the time of rehydration. Irrespectively of the final quantities of metabolites obtained in this process, key differences were observed at the genetic level at the initial stage of rehydration, as the results of RT qPCR analysis of the tested genes GPD1 and SIP18 showed differences in the expression of these genes in variable rehydration media.

As shown in results, the fermentation rate of young ciders was closely associated with ethanol production and sugar consumption. Statistically minor differences in fermentation parameters due to the time of rehydration of inoculated cells were probably caused by adaptation to the environments of higher osmolarity not only during rehydration but also in the fermentation flask. The change consists of induction of the HOG pathway and transduction of the signal responsible for glycerol biosynthesis. The most interesting fact was that yeast cells immediately adapted to changes during rehydration, particularly to the content of hexose sugars in the medium. This was best illustrated in the case of GPD1 gene, with its expression levels increasing statistically significantly as early as after 5 minutes of rehydration in a medium with elevated $-300 \mathrm{~g}^{-1}$ concentration of sugar. The effect was more profound at further time points.

The research group of Vaudano (2009) used the RT qPCR method to study the expression of MEP1, MEP2 and $M E P 3$ genes responsible for nitrogen transport as well as the GPD1 and SIP18 genes as tested in this study in dried yeast cells upon rehydration. The laboratory media consisted of water containing $5 \%$ sucrose, $6.0 \mathrm{mM}$ ammonium ions and combination of the latter. In the context of the expression of genes tested in this study, the authors demonstrated small differences present at very low levels in the transcription of the GPD1 gene regardless of rehydration time. Examining the same genes demonstrated that GPD1 is highly expressed during the drying stage and high transcriptional level may be maintained at the early phase of rehydration. Rossignol et al. (2006) were not able to demonstrate an increase in the expression of this gene in the first hour of rehydration; according to the authors, the expression of the gene was dropping. However, statistically significant increase was observed in the sixth hour of rehydration, possibly suggesting that osmotic stress may be transient and the 
earlier experiment did not last long enough to make it observable. The obtained result suggest that cells may change their expression profiles. The tested strains are converted from dry state directly into an environment that is not only hydrated, but also contains an elevated sugar concentration. The increased level of glycerol inside the cell leads to a reduced activity of water in cytosol thus reducing the outflow of water into the environment. Glycerol production is, therefore, indeed essential for the growth of yeast cells in periods of reduced water availability. During our studies Saccharomyces cerevisiae cells were rehydrated using media with concentrations of sugars much higher than abovementioned. The differences in the results may be due to the use of a different type of media, industrial rather than laboratory, being significantly different in terms of sugar levels. The higher densities of apple must induce higher stress responses upon hydration and faster adaptation of cells to the final environment. The tested strains prepare for increased production of glycerol which requires the suppression of excess water loss by cells in the current situation. The obtained results do not have to be relevant for the entire population of Saccharomyces cerevisiae due to its heterogeneity; total mRNA screening might not provide a clear indication of the degree of cellular response to osmotic stress.

Similarly to our experiments, the increasing expression of GPD1 gene in yeast cells may be confirmed by the results obtained by Perez-Torrado and coworkers (2005) who demonstrated increased mRNA levels in the industrial T73 strain after the first hour of incubation in wine must of elevated sugar concentration. No appropriate time to measure the expression was identified in case of another industrial strain IFI87; the authors suggested that only the final stage of induction was observed after 2.5 hours. The reactions to high levels of sugars may also be strain-specific. Attfield and Kletsas (2000) demonstrated that GPD1 induction was highly dependent on the test strain selection - sugar levels around $300 \mathrm{~g} \mathrm{l}^{1}$ induced the transcription of the gene in SC13 strain after 30 minutes of the test (with highest levels observed after 60 minutes); in case of the SC9 strain, the highest level was observed after 120 minutes.

Different correlations were observed for the expression of SIP18 gene. It codes proteins which play a role as antioxidants and as membrane and protein stabilizers during water stress (Tunnacliffe \& Wise, 2007). The study revealed a significant decrease in SIP18 expression during the entire experiment. As shown by our own results, as well as by these obtained by the research team of Rossignol (2006), the gene is activated upon drying and, therefore, shows elevated mRNA levels already at the beginning of the experiment. The authors observed a very clear decrease in the expression of the gene occurring gradually within 6 hours of the experiment, as assayed by Northern blot and DNA microarrays. Studies by Singh (2005) confirmed that SIP18 is transcribed during the drying phase and maintains high expression levels for some time upon rehydration. This was demonstrated by the comparison of tested strains with commercial ADY samples used in wine-making industry. The mRNA levels of SIP18 were high and sample-independent. The research team of Vaudano (2009) also demonstrated elevated transcription of SIP18 at levels observed in this experiment. Conditions of RT qPCR analysis used in the experiment were similar despite of the differences in the reference genes used for interpretation of the results. The lower decrease of expression levels as compared to the studies by Rossignol (2006) was also due to the shorter duration of the experiment (30 minutes instead of 6 hours); it might also have been affected by the selection of tested strain and the type of rehydration media.

As shown by the results of the experiments, the cell environment has a significant impact on the molecular reactions occurring inside the cells. Water is probably inefficient as rehydration medium, which is an evidence of gene expression being dependent on the presence of carbon within the rehydration medium. The changes in osmolarity of the rehydration medium clearly stimulate the expression of the main gene of the HOG metabolic pathway, i.e. GPD1. As suggested by high mRNA levels of SIP18, the drying process also dramatically affects the cell, markedly modulating its translation apparatus. Differences in the expression levels observed in the experiments may be strain-specific and due to individual characteristics or the origin of the strains.

\section{Acknowledgements}

This IAFB statutory work was supported by the Ministry of Science and Higher Education of the Polish government.

\section{REFERENCES}

Albertyn J, Hohmann S, Prior BA (1994) Characterization of the osmotic-stress response in Saccharomyces cerevisiae: osmotic stress and glucose repression regulate glycerol-3-phosphate dehydrogenase independently. Curr Genet 25: 12-18. doi:10.1007/bf00712960

Attfield PV, Kletsas S (2000) Hyperosmotic stress response by strains of bakers' yeasts in high sugar concentration medium. Lett Appl Microbiol 31: 323-327. doi:10.1046/j.1472-765x.2000.00825.x

Babazadeh R, Fukurawa T, Hohmann S, Furukawa K (2014) Rewiring yeast osmostress signalling through the MAPK network reveals essential and non-essential roles of Hog1 in osmoadaptation. Sci Rep 4: 4697. doi: 10.1038/srep04697

Bauer FF, Pretorius IS (2000) Yeast stress response and fermentation efficiency: how to survive the making of wine-a review. $S$ Afr J Enol Vitic 21: 27-25

Cerrutti P, Segovia de Huergo M, Galvagno M, Schebor del Pilar C, Del Pilar Buera M (2000) Commercial baker's yeast stability as affected by intracellular content of trehalose, dehydration procedure and the physical properties of external matrices. Appl Microbiol Biot 54: 575-580. doi: $10.1007 / \mathrm{s} 002530000428$

Chambers PJ, Pretorius IS (2010) Fermenting knowledge: the history of winemaking, science and yeasts research. EMBO Rep 11: 1291412920. doi:10.1038/embor.2010.179

Diaz-Hellin P, Gómez-Alonso S, Borrull A, Rozès N, Cordero-Otero R, Úbeda J (2014) Membrane lipid variability in Saccharomyces cerevisiae wine strains rehydrated in the presence of metabolic activators. J Agric Food Chem 62: 8679-8685. doi: 10.1021/jf500895y

Ferrarini R, Bocca E, Cavazza A (2007) Mechanical dispersion procedures improve the rehydration of active dry yeast. Enzyme Microb Tech 40: 1251-1255. doi: 10.1016/j.enzmictec.2006.09.021

Fu N, Chen XD (2011) Towards a maximal cell survival in convective thermal drying processes. Food Res Int 44: 1127-1149. doi: 10.1016/j.foodres.2011.03.053

Gamero-Sandemetrio E, Gomez-Pastor R, Matallana E (2014) Antioxidant defense parameters as predictive biomarkers for fermentative capacity of active dried wine yeast. Biotechnol J 9: 1055-1064. doi: 10.1002/biot. 201300448

Gomez-Pastor R, Perez-Torrado R, Cabiscol E, Ros J, Matallana E (2010) Reduction of oxidative cellular damage by overexpression of the thioredoxin TRX2 gene improves yield and quality of wine yeast dry active biomass. Microb Cell Fact 9: 9. doi: 10.1186/1475-2859-9-9

Gasch AP, Spellman PT, Kao CM, Carmel-Harel O, Eisen MB, Storz G, Botstein D, Brown PO (2000) Genomic expression programs in the response of yeast cells to environmental changes. Mol Biol Cell 11: 4241-4257. doi:10.1091/mbc.11.12.4241

Hohmann S (2002) Osmotic stress signaling and osmoadaptation in yeasts. Microbiol Mol Biol Rev 66: 300-372. doi:10.1128/ mmbr.66.2.300-372.2002

Hubmann G, Guillouet S, Nevoigt E (2011) Gpd1 and Gpd2 fine-tuning for sustainable reduction of glycerol formation in Saccharomyces cerevisiae. Appl Environ Microbiol 77: 5857-5867. doi:10.1128/AEM. 05338-11 
Ilnicka-Olejniczak O, Misiewicz A, Juszczakiewicz D (1996) Biotechnological properties of Saccharomyces cerevisiae winery yeasts deposited in Culture Collection of Industrial Microorganisms CCIM. Pr Inst Lab Bad Przem Spoż 51: 95-106 (in Polish)

Kraus JK, Scopp R, Chen SL (1981) Effect of rehydration on dry wine yeast activity. Am J Enol Viticult 32: 132-134

Lee BH (2015) Fundamentals of Food Biotechnology. John Wiley \& Sons. doi: 10.1002/9781118384947

Livak KJ, Schmittgen TD (2001) Analysis of relative gene expression data using real-time quantitative PCR and the 2(-Delta Delta C(T)) Methods 25: 402-408. doi: 10.1006/meth.2001.1262

Mager WH, Sigerius M (2002) Novel insights into the osmotic stress response of yeast. FEMS Yeast Res 2: 251-257. doi: 10.1111/j.15671364.2002.tb00092.x

Mannazzu I, Angelozzi D, Belviso S, Budroni M, Farris GA, Goffrini P, Lodi T, Marzona M, Bardi L (2008) Behavior of Saccharomyces cerevisiae wine strains during adaptation to unfavorable conditions of fermentation on synthetic medium: cell lipid composition, membrane integrity, viability and fermentative activity. Int J Food Microbiol 121: 84-91. doi: 10.1016/j.ijfoodmicro.2007.11.003.

Mercado L, Combina M (2010) Expolring the biodiversity od a wine region: Saccharomyces yeasts associated with wineries and vineyards. Current Research, Technology and Education Topics in Applied Microbiology and Microbial Biotechnology. A. Mendez-Vilasee eds, pp 1042--1053

Mercado L, Sturm ME, Rojo MC, Ciklic I, Martinez C, Combina M (2011) Biodiversity of Saccharomyces cerevisiae populations in Malbec vineyards from the "Zona Alta del Rio Mendoza" region in Argentina. Int J Food Microbiol 151: 319-326. doi: 10.1016/j.iifoodmicro.2011.096.026

Miller GL (1959) Use of dinitrosalicylic acid reagent for determination of reducing sugar. Anal Chem 31: 426-428. doi: 10.1021/ ac60147a030

Misiewicz A, Ilnicka-Olejniczak O (1996) The characteristics of some brewers' yeast strains. Pol J Food Nutr Sci 5: 95-99

Misiewicz A, Wetoszka U, Spera M, Kieliszek M (2015) Method for honey wort high-sugar alcohol fermentation. Patent: WO2015102500-A1; PL40671813-A1; EP2914755-A1

Misiewicz A, Ilnicka-Olejniczak O (1991). Influence of storage of Saccharomyces cerevisiae wine yeasts in $-80^{\circ} \mathrm{C}$ to quality of young wine. Pr Inst Lab Bad Przem Sp 45: 157-164 (in Polish)

Nardi T, Corich V, Giacomini A, Blondin B (2010) A sulphite-inducible form of the sulphite efflux gene SSU1 in a Saccharomyces cerevisiae wine yeast. Microbiology 156: 1686-1696. doi: 10.1099/mic.0.036723-0

Novo M, Beltran G, Rozes N, Guillamon JM, Sokol S, Leberre V, Mas A (2007) Early transcriptional response of wine yeast after rehydration: osmotic shock and metabolic activation. FEMS Yeast Res 7: 304-316. doi: 10.1111/j.1567-1364.2006.00175.x

Peña A, Uribe S, Clemente M, Sánchez N (1992) Rehydration temperature is critical for metabolic competence and for membrane integrity in active dry yeast (ADY) Arch Microbiol 158: 75-80. doi: $10.1007 / \mathrm{bf00245208}$

Pénicaud C, Landaud S, Jamme F, Talbot P, Bouix M, Ghorbal S, Fonseca F (2014) Physiological and biochemical responses of Yarrowia lipolytica to dehydration induced by air-drying and freezing. PLOS ONE 9: e111138. doi: 10.1371/journal.pone.0111138

Pérez-Torrado R, Bruno-Bárcena JM, Matallana E (2005) Monitoring stress-related genes during the process of biomass propagation of Saccharomyces cerevisiae strains used for wine making. Appl Environ Microbiol 71: 6831-6837. doi: 10.1128/aem.71.11.6831-6837.2005

Pérez-Torrado R, Carrasco P, Aranda A, Gimeno-Alcañiz J, PérezOrtín JE, Matallana E, del Olmo ML (2002) Study of the first hours of microvinification by the use of osmotic stress-response genes as probes. Syst Appl Microbiol 25: 153-161. doi: 10.1078/07232020-00087

Petelenz-Kurdziel E, Kuehn C, Nordlander B, Klein D, Hong KK, Jacobson T, Dahl P, Schaber J, Nielsen J, Hohmann S, Klipp E. (2013) Quantitative analysis of glycerol accumulation, glycolysis and growth under hyper osmotic stress. PLoS Comput Biol 9: e1003084. doi:10.1371/journal.pcbi.1003084

Pfaffl MW, Tichopad A, Prgomet C, Neuvians TP (2004) Determination of stable housekeeping genes, differentially regulated target genes and sample integrity: BestKeeper-Excel-based tool using pair-wise correlations. Biotechnol Lett 26: 509-515. doi: 10.1023/b:b ile.0000019559.84305.47

PN-90 A-791120/04. Content of density of ethanol using aerometric method according PN90 A-79120/04. (in Polish)
PN-90 A-79120/05. Wines and meads. Samples preparation and testing methods. Marking method of content of total extract in wines and meads using measurement density method and manner of calculating of extract content. (in Polish)

PN-90 A-79120/07. Wines and meads. Samples preparation and testing methods. Marking of total acidity. Methods of marking of total acidity using potentiometric titration (appealing method), titration method with bromocresol blue. (in Polish)

PN-90 A-79120/08. Wines and meads. Samples preparation and testing methods. Marking of volatile acidity. (in Polish)

PN-ISO 21527-1:2009. Microbiology - General guidance for enumeration of yeasts and moulds. Colony count technique at $25^{\circ} \mathrm{C}$. (in Polish)

Posas F (1998). Activation of the yeast SSK2 MAP kinase kinase kinase by the SSK1 two-component response regulator. EMBO J 17: 1385-1394. doi:10.1093/emboj/17.5.1385

Pretorius IS (2000) Tailoring wine yeasts for the new millennium: novel approaches to the ancient art of winemaking. Yeast 16: 675-729. doi: 10.1002/1097-0061(20000615)16:8,675::AID-YEA585.3.3.CO;2$\mathrm{B}$

Rodriguez-Peña JM, Garcia R, Nombela C, Arroyo J (2010) High-osmolarity glicerol (HOG) and cell wall integrity (CWI) signaling pathways interplay: a yeast dialogue between MAPK routes. Yeast 27: 495-502. doi:10.1002/yea.1792

Rodríguez-Porrata B, Carmona-Gutierrez D, Reisenbichler A, Bauer M, Lopez G, Escoté X, Mas A, Madeo F, Cordero-Otero R (2012) Sip18 hydrophilin prevents yeast cell death during desiccation stress. I Appl Microbiol 112: 512-525. doi: 10.1111/j.1365-2672.2011.05219.x

Rodríguez-Porrata B, López-Martínez G, Redón M, Sancho M, Mas A, Rozès N, Cordero-Otero R (2010) Enhancing yeast cell viability after dehydration by modification of the lipid profile. World J Microb Biot 27: 75-83. doi: 10.1007/s11274-010-0428-1

Rosini G (1984) Assessment of dominance of added yeast in wine fermentation and origin of Saccharomyces cerevisiae in wine-making, J Gen Appl Microbiol 30: 249-256. doi:10.2323/igam.30.249

Rossignol T, Postaire O, Storai J, Blondin B (2006) Analysis of the genomic response of a wine yeast to rehydration and inoculation. Appl Microbiol Biot 71: 699-712. doi: 10.1007/s00253-006-0398-2

Sales K, Brandt W, Rumbak E, Lindsey G (2000) The LEA-like protein HSP 12 in Saccharomyces cerevisiae has a plasma membrane location and protects membranes against desiccation and ethanolinduced stress. Biochim Biophys Acta 1463: 267-278. doi: 10.1016/ s0005-2736(99)00215-1

Singh J, Kumar D, Ramakrishnan N, Singhal V, Jervis J, Garst J, Slaughter S, DeSantis A, Potts M, Helm R (2005) Transcriptional response to Saccharomyces cerevisiae to desiccation and rehydration. Appl Environ Microb 17: 8752-8763. doi: 10.1128/aem.71.12.87528763.2005

Soubeyrand V, Julien A, Sablayrolles J-M (2006) Rehydration protocols for active dry wine yeast and the search for early indicators of yeast activity. In. Am J Enol Viticult 52: 474-480

Szterk A (2015) Acridine derivatives (PANHs, azaarenes) in raw, fried or grilled pork from different origins, and PANH formation during pork thermal processing. I Food Compost Anal 43: 18-24. doi: 10.1016/j.jfca.2015.04.011

Tunnacliffe A, Wise MJ (2007) The continuing conundrum of the LEA proteins. Naturwissenschaften 94: 791-812. doi: 10.1007/s00114-0070254-y

Valasek MA, Repa JJ (2005) The power of real-time PCR. Adv Physiol Educ 29: 151-159. doi: 10.1152/advan.00019.2005

Valero E, Cambon B, Schuller D, Casal M, Dequin S (2007) Biodiversity of Saccharomyces yeast strains from grape berries of wineproducing areas using starter commercial yeasts. FEMS Yeast Res 7: 317-329. doi: 10.1111/j.1567-1364.2006.00161.x

Vaudano E, Costantini A, Cersosimo M, Del Prete V, Garcia-Moruno E (2009) Application of real-time RT-PCR to study gene expression in active dry yeast (ADY) during the rehydration phase. Int J Food Microbiol 129: 30-36. doi: 10.1016/j.ijfoodmicro.2008.10.027

Vaudano E, Costantini A, Noti O, Garcia-Moruno E (2010) An RTqPCR approach to study the expression of genes responsible for sugar assimilation during rehydration of active dry yeast. Food Microbiol 27: 802-808. doi: 10.1016/j.fm.2010.04.010

Vaudano E, Noti O, Costantini A, Garcia-Moruno E (2014) Effect of additives on the rehydration of Saccharomyces cerevisiae wine strains in active dry form: influence on viability and performance in the early fermentation phase. J Inst Brew 120: 71-76. doi: 10.1002/jib.114 